\title{
Policy, practice and process in team teaching: a pilot project with co-operating teachers and student teachers on school placement
}

\section{Angela Rickard \& Thomas Walsh}

To cite this article: Angela Rickard \& Thomas Walsh (2019) Policy, practice and process in team teaching: a pilot project with co-operating teachers and student teachers on school placement, Irish Educational Studies, 38:3, 309-326, DOI: 10.1080/03323315.2019.1625798

To link to this article: https://doi.org/10.1080/03323315.2019.1625798

曲 Published online: 04 Jun 2019.

Submit your article to this journal $\pi$

III Article views: 461

Q View related articles ¿

View Crossmark data \lceil 


\title{
Policy, practice and process in team teaching: a pilot project with co-operating teachers and student teachers on school placement
}

\author{
Angela Rickard* and Thomas Walsh \\ Department of Education, Maynooth University, Maynooth, Ireland
}

(Received 27 September 2016; accepted 28 May 2019)

In Ireland, at present, the roles and responsibilities of the educational partners regarding initial teacher education (ITE) are in transition. ITE routes have been extended allowing for additional focus to be placed on the central component of school placement. This material change, as well as policies promoting collaborative practice, teachers as researchers and professional learning communities (PLCs), prompted us to reflect on our practice and to challenge assumptions in relation to teaching and learning. Among the outcomes of the work was a reassessment and reorientation of current approaches on the Professional Master of Education (PME) programme to better prepare student teachers for their future careers in post-primary schools.

This article reports on the development of and findings from a team teaching pilot project in the Department of Education of Maynooth University for student teachers and their co-operating teachers. The project was undertaken to provide space for the participants, including the authors, to reappraise the approach to teacher education, to explore the team teaching process, to focus on its affective dimension and foster collaborative practices in education.

Keywords: initial teacher education (ITE); team teaching; collaboration; school placement; university-school partnership; post-primary education; professional learning communities (PLCs)

\section{Introduction}

The main aim of this paper is to present the rationale for a team teaching research project undertaken between the Department of Education in Maynooth University and a number of partner schools, to situate it within the national and international practice and research context and to present the key findings and implications of the work. The purpose of the research project was to facilitate the development of collaborative practice between individual student teachers and their co-operating teachers and it is in keeping with the increased emphasis on the development of critically reflective practice in teacher education (Tabachnick and Zeichner 1991; Ball and Cohen 1999). At our Department, team teaching by student teachers with their cooperating teachers is promoted and encouraged as an approach for school placement and appears in course documentation for the Professional Master of Education (PME). However, our own practice on the programme had not included a team teaching approach nor did we explicitly support our student teachers for this complex

\footnotetext{
*Corresponding author. Email: angela.rickard@mu.ie 
expectation. The current research project was undertaken to provide the space for ourselves, our student teachers and their co-operating teachers to explore aspects of team teaching in a safe and supportive environment, to engage confidently and effectively in it, and to develop and share our respective understandings of the processes involved. The project was supported by a collaboration with the Professional Development Service for teachers (PDST), whose remit is to promote teacher professional development, including teacher collaboration.

A key objective of the research was to explore the process around team teaching and to focus on elements of the affective domain that was impacted by this process, as ' ... so much of the research stands accused of failing to interrogate the process at the expense of certain more easily measurable, though not necessarily more important, summative achievements' (Murphy 2011, 65). It is in exploring the relationships, motivations, cultures, attitudes and beliefs of student teachers and teachers that greater understanding of the willingness and capacity to engage in team teaching will emerge.

Below we outline the national policy context concerning team teaching and offer a definition of the term before examining the research literature in the area from both international and Irish perspectives. The methodology and action-based reflexive approach taken in the project are then delineated. Key findings from the research are presented before concluding with a discussion of the insights from it and an outline of its development and extension into the future.

\section{Literature review}

\section{Research literature on team teaching}

Despite an increased interest in and emphasis on teacher collaboration to improve outcomes for all students (Ball and Cohen 1999; Lieberman and Miller 2008) as well as value being placed on inclusive practice in the context of children with special educational needs (SEN) (NCSE 2011; Rix et al. 2013; O'Leary 2015) team teaching has been under-researched both internationally (Weiss and Brigham 2000; Murawski and Lee Swanson 2001; Dieker 2015; Thompson et al. 2015) and in Ireland (Shevlin et al. 2009; McNamara 2010; Murphy 2011). Hattie's (2009) meta-analysis of studies relating to team teaching notes that many of the research projects were small scale in nature. As he states, ' ... there is a dearth of literature on the effects of team teaching, which probably reflects its absence in our schools' (Hattie 2009, 219). Dieker, writing about co-teaching, asserts that 'despite the increasing popularity of this service delivery model the field currently lacks a strong database of the overall effectiveness of the model' (2015, np).

Murphy (2011) undertook a meta-analysis of 46 relevant studies relating to team teaching in post-primary contexts published in the previous 15 years and reports that the impact of team teaching on pupils' learning and its potential in the delivery of inclusive education is under-researched. Due to the small-scale nature and short timeframe associated with much of the research on team teaching, findings concerning its effectiveness to improve academic or other outcomes have often proven inconclusive (Hattie 2009; Murphy 2011).

Team teaching places the locus for teacher professional development in school and provides a context for teacher expertise to be unleashed and shared. As stated by Lieberman and Miller $(2008,22)$ : 
Much of the current professional development activity rests on the assumption that there are best practices out there. In professional learning communities, this belief is replaced by the conviction that the best practices are in here; they can be uncovered by mining inside knowledge.

Cook and Friend (1991) outline the key principles for collaboration in schools and note that time is required for respect and trust to develop before deep and meaningful collaboration is possible. A recent review undertaken by Fluijt, Bakker, and Struyf (2016) also emphasises team-reflection as an essential component in the development of shared vision of team teaching as an educational practice for teachers and concludes that 'most challenges they have to face are interpersonal' (197). Research indicates that a number of factors impact on the effectiveness of team teaching approaches. These include the provision of training and time for teachers to plan and engage in team teaching (Dieker and Murawski 2003; Simmons and Magiera 2007) and respect and professional parity between team teachers (Cramer and Nevin 2006; Scruggs, Mastropieri, and McDuffie 2007) and crucially, time for reflection (Fluijt, Bakker, and Struyf 2016).

\section{Team teaching in initial teacher education}

Until relatively recently, team teaching had not featured prominently in pre-service teacher education programmes internationally (Burbank and Kauchak 2003; Hume and Berry 2013) nor in the Irish context (Murphy 2011; Rickard and Dempsey 2013). This is no doubt affected by issues such as sustainability, scalability and replication (Miller and Stayton 1999; Murphy 2016). The last decade or more has seen team teaching being promoted as an alternative to traditional teaching (Zeichner 2002; Wassell and LaVan 2009), as a valuable way to learn about teaching (Eick, Ware, and Williams 2003; Tobin 2006), in particular about pedagogical content knowledge (Scantlebury, Gallo-Fox, and Wassell 2008; van Velzen et al. 2012). A review of international practices relating to children with SEN (Rix et al. 2013) identifies team teaching as an approach that is not widely practised and it concludes that there is need for further opportunities at ITE and for continuing professional development (CPD) around experiencing collaboration and effective team teaching. Scantlebury, Gallo-Fox, and Wassell (2008, 967), writing about a three-year initiative to introduce team teaching in a post-primary ITE programme in the United States, note that:

Research has focused on the isolation new teachers face in the classroom, yet few practicum models or professional development programs seek to address the inherent isolation in teaching.

Much of the research notes the capacity for team teaching to bridge the theory-practice gap (Baeten and Simons 2014) and to counteract the isolation felt by many preservice and beginning teachers and it has been posited as an effective way to 'immerse student teachers in the culture of the school helping them to learn "by working closely at the elbows of their mentor teacher" (Carambo and Stickney 2009 , 434). Team teaching is also valued as a way to encourage reflective practice as much for established teachers as among student teachers (Burbank and Kauchak 2003). 
Wassell and LaVan (2009) explore how team teaching can lead to greater confidence among beginning teachers and a greater likelihood that they will continue to embrace collaborative practice as their careers develop. Baeten and Simons (2014, 99) assert that team teaching is advantageous to student teachers as it 'encourages emotional and professional support and dialogue about teaching and learning'. However, Hume and Berry $(2013,2108)$ bemoan the regression to traditional teaching practices among NQTs, noting the overall dearth of team teaching in ITE and pointing out that:

While pockets of success exist, it is a concern that pedagogies known to affect quality teaching and learning are not being widely practiced despite their promotion in teacher education.

Carambo and Stickney $(2009,435)$ highlight the opportunities that even disagreements between teachers provide to challenge assumptions and '.. orthodox, habituated thoughts' and to force them to re-examine their perspectives ' ... in light of those represented by [their] co-teachers'. This point is also considered as an advantage by Baeten and Simons $(2014,99)$ who note in relation to team teaching among student teachers that 'discovering professional and personal weaknesses through the comparison with a peer may be perceived as a starting point for change and growth'. However, issues of power differential and confidence are important considerations between cooperating teachers and student teachers in this context (Lofthouse and Thomas 2014).

\section{Definitions of team teaching}

There are multiple definitions of team teaching in the literature (Welch, Brownell, and Sheridan 1999; Roth and Tobin 2002; Villa, Thousand, and Nevin 2008; Friend et al. 2010; Fluijt, Bakker, and Struyf 2016) and indeed there are many synonyms for the practice that are often used interchangeably in Ireland and internationally. The term 'co-teaching' has gained prominence internationally as an umbrella term to cover practices such as 'team teaching', 'collaborative teaching' and 'co-operative teaching'. However, in Ireland, despite the use of a range of terms in policy documents and in the general parlance of educationalists, the term 'team teaching' has greatest resonance among post-primary teachers and schools. Moreover, as indicated by Murphy (2011), the term 'team teaching' indicates that there are many parties involved in the team process (including pupils) and it gives a greater sense of engagement, involvement and ownership rather than focusing on the binary relationship of the teachers, that the term 'co-teaching' implies. The definition of team teaching used throughout this article emanates from a County Cork Vocational Educational Committee (VEC) Project in 2011 which defines it as follows:

Team teaching is when two (or more) teachers share the instructional responsibility for a class, including planning and evaluation. They share the leadership of the class and responsibility for all students. (County Cork VEC 2011, 5)

Six dominant models of team teaching have emerged from the literature on a continuum from a scenario where one teacher leads and the other supports through to a situation where there is equal and shared responsibility (Villa, Thousand, and Nevin 2008; Baeten and Simons 2014). 


\section{Irish policy context}

Since 2014, postgraduate ITE routes for post-primary teachers in Ireland have been extended to two years, leading to a new qualification, the PME. The change allows additional focus to be placed on the central component of school placement and enables student teachers to gain a wider repertoire of experiences and further develop their pedagogical practice in preparation for a career in teaching (Teaching Council 2013). The Teaching Council (2013) also advocates the fostering of stronger university-school partnerships as part of the future development of initial teacher education (ITE). The changes to curriculum and assessment (Department of Education and Skills [DES] 2012) and an emphasis on 'teachers as researchers' (Kincheloe 2012; Gray 2013; British Educational Research Association [BERA] 2014) also increase the demands on teachers and student teachers.

Support for collaborative practice and team teaching in Ireland stems mainly from government policy position of integration and inclusion espoused by the Education Act (DES 1998) and Education for Persons with Special Educational Needs (EPSEN) Act (Government of Ireland 2004) respectively. DES guidelines on inclusion (DES 2007) and circulars (DES 2014) advocate team teaching as an approach to promote inclusion of pupils with special educational needs (SEN) in schools. Team teaching is also advocated by the National Educational Psychological service (NEPS) (NEPS 2010) and by the National Council for Special Education (NCSE) (NCSE 2011, 2013, 2015) as a practice that facilitates inclusion. It is in this context that most teachers in Ireland have been introduced to or engaged in team teaching and there is still a strong association between team teaching and catering for pupils with SEN. However, such policy is slow to translate into practice in the absence of comprehensive supports and many reports have noted the tendency to withdraw pupils with SEN rather than support them in class through practices such as team teaching (Irish Association of Teachers in Special Education [IATSE] 2000; O'Gorman et al. 2009; Travers et al. 2010; DES 2018).

More recent policy initiatives from the DES have focused on the importance of teacher collaboration as a central principle underpinning their work. This is evident in the national literacy and numeracy strategy, Literacy and Numeracy for Learning and Life (DES 2011). Greater professional collaboration between teachers is also a central principle in the Joint Statement on Principles and Implementation of Junior Cycle reform published by the teacher unions and the DES in 2015 (Teachers' Union of Ireland, Association of Secondary Teachers Ireland and DES 2015). Teacher collaboration is also central to the school self-evaluation guidelines (DES 2016a), which advocate team teaching and professional collaborative review as strategies for evidence gathering. Moreover, one of the four domains of the Quality Framework to be used for both internal evaluation by schools and by external inspection models is 'teachers' collaborative and collective practice' (DES 2016b). This advocates professional collaboration and a greater sharing of teacher expertise in schools.

Team teaching is also relevant to the current work of the Teaching Council in Ireland as it articulates and designs a framework around the continuum of teacher education (Teaching Council 2011). In Cosán, the Teaching Council's Framework for Teachers' Learning (Teaching Council 2016), activities such as team teaching, supporting colleagues to develop their teaching, engaging in collective reflection, working as a co-operating teacher and engaging in professional conversations with colleagues, 
are listed as possible professional development activities for teachers. This perspective resonates strongly with the work of the National Induction Programme for Teachers (NIPT), which supports the induction and probation of both primary and postprimary NQTs into the teaching profession in Ireland.

Murphy (2011) argues that while team teaching is promoted as an approach at a policy level, its enactment at a practice level is left to fate. Despite evidence that team teaching has gained relatively low levels of traction in post-primary schools, Shevlin et al. (2009) note that there is an appetite among teachers to understand how to use team teaching as part of their professional practice. The research suggests that participation in team teaching and active professional collaboration, practices associated with progressive professionalism, remains a challenge for many teachers in Ireland (Hogan et al. 2007; Organisation for Economic Co-operation and Development [OECD] 2009; Murphy 2011; Gleeson 2012).

This research project supports the national policy stance by breaking down many of the traditional barriers between the various stages of the teacher education continuum. It allows for much of the professional engagement to happen and confidence to develop at a classroom and school level in order to make the experience more authentic. Before turning to the research design, method and findings from this pilot project we will briefly explore team teaching in Irish schools.

\section{Team teaching in Irish schools}

While there were some efforts at facilitating team teaching in primary schools in the 1970s through the introduction of shared areas in school designs (McKenna 1982; Irish National Teachers' Organisation 1984), there was no parallel movement at post-primary level. Moreover, the limited number of small-scale research projects on team teaching in Ireland relate predominantly to contexts involving provision for pupils with SEN (Bates 2005; Nolan 2005; McNamara 2010). Conway (2002) labels the post-primary classroom in Ireland as a 'secret garden' given the relative privacy in which teaching was undertaken. In its review of education in Ireland in 1991 with a particular focus on teacher education, the OECD team notes the legendary autonomy of teachers in classrooms and laments the didactic nature of teaching, with no examples of team teaching observed (OECD 1991, 103).

While issues of time and the timetabling of team teaching are challenging, it is arguable that the real complexity emerges in the personal and professional relationships that team teaching demand of teachers who ordinarily work alone. Murphy $(2011,91)$ notes that 'teacher compatibility' is the variable most frequently referenced in the 46 studies analysed as part of his doctoral work. In a longitudinal study with a number of post-primary schools in Ireland as part of the Teaching and Learning for the Twenty-first Century (TL21) study, Hogan et al. $(2007,34)$ note ' ... the prevalence of professional insulation and isolation, as distinct from proactive professional cooperation, in the inherited cultures of post-primary education in Ireland'. Gleeson (2012) draws a similar conclusion in relation to the lack of professional collaboration in Irish schools.

These views on the lack of opportunities for post-primary teachers to work collaboratively with their colleagues were evidenced in the 2009 OECD Teaching and Learning International Survey (TALIS). It reports that instances of both 'Exchange and Co-ordination of Information' and 'Professional Collaboration' were lower in 
Ireland than the OECD average (OECD 2009). For example, 95\% of teachers had never been engaged in teacher observation and feedback or did so less than once a year, only $18 \%$ had visited another teacher's classroom and $76 \%$ had never engaged in team teaching or did so less than once a year. Therefore, much of the existing collaboration in Irish post-primary schools among teachers, when it happened at all, was undertaken away from classrooms.

A longitudinal team teaching project alluded to earlier that was undertaken by County Cork VEC since 2007 has reported positive results regarding the impact of team teaching (County Cork VEC 2011). Some of the positive outcomes for pupils who were team taught during the project include improved scores on standardised tests in literacy and numeracy, higher than expected results in state examinations, improved levels of pupil attendance, engagement, participation, confidence and attitudes. Teachers involved also report the positive impact of being involved in team teaching, including an enhanced sense of professional belonging, learning new methodologies and retuning to forgotten good practice, having time for reflection during lessons and forming new professional relationships (Inclusive Education in Action 2016). Similar findings have emerged in case study research relating to pupils with SEN in Ireland (O'Leary 2015).

It is in this research, policy and practice context that the project described in this article was undertaken. The next section outlines the research design and methods.

\section{Research design and methods \\ Research paradigm and approach}

Taking a view of learning as culturally situated and socially constructed (Brown, Collins, and Duguid 1989), our research approach was characterised by an emphasis on peer interaction and critical reflection (Barnett 1997; Biesta 2011). In keeping with the idea of reflective research for rather than on teaching, we sought 'to emulate in [our] work as teacher educators the reflectiveness that [we] seek to develop in [our] students' (Tabachnick and Zeichner 1991, xi) and to model team teaching and collaboration while encouraging student teachers and their cooperating teachers to also work collaboratively. The research therefore was participatory and exploratory and it evolved to respond to the participants' needs. Mindful of the observation by Murphy (2011) about the difficulty in measuring the affective dimension of experiences, we sought to explore rather than 'measure' this. So in the spirit of exploratory practice we probed our various sources of data for what they might reveal of the participants' feelings about being involved.

\section{Research participants and process}

The research participants were 15 student teachers and their co-operating teachers in partner schools and the two authors of this research paper. Modelling the values of openness and risk-taking in our own practice and exposing ourselves to the same vagaries and vulnerabilities inherent in team teaching as those our student teachers and their co-operating teachers would encounter (Lofthouse and Thomas 2014) added authenticity to the process and we openly 'confessed' to our inexperience of team teaching at the start. The participatory nature of the project gave us scope to create resources and materials to probe participants' attitudes to team teaching. It also 
enabled us to facilitate discussions about team teaching by the participants in their own wider school community. Indeed, this was a 'condition' of the teachers' involvement and was in keeping with national policy to promote the leading of learning within the schools (Teaching Council 2016).

Having established ethical approval for the research under the auspices of the university's ethical procedures, informal contacts were made with the student teachers and school leaders to introduce and discuss the project in January 2015. These professional conversations were also used as a method to refine the research design and questions further. Principals were asked to discuss the project with teachers and to nominate a teacher who would be willing to participate in it. Fifteen designated cooperating teachers were subsequently officially invited to participate in the project alongside their assigned student teacher (30 participants in total).

An information letter was sent to each school outlining the aims of the research and the process for the pilot project. Two workshops were organised in the university to support co-operating teachers and student teachers to participate in the project. The first workshop in February 2015 was designed to explore models of team teaching and to prepare participants to team teach a lesson or series of lessons. Following the first workshop, each pairing (co-operating teacher and student teacher) was invited to plan, team teach and reflect on the process. During the second university-based workshop in March 2015, participants engaged in active structured reflection on the lessons taught, distilled the key learning from this, and planned a presentation to be made within their schools and to the wider educational community in a seminar co-organised by the university and the PDST. The project culminated in this seminar showcase event in April 2015. The event provided an opportunity for teachers to formally share artefacts and insights from their lessons in poster format; to engage with invited principals, researchers and policy makers in the area of team teaching; to articulate their views on the team teaching experience and to inform practice that would extend beyond the research project.

\section{Research methods}

Document analysis (Bowen 2009) was used to inform the development of both an entry questionnaire (at the first workshop) and an exit questionnaire (at the second workshop). These consisted of a series of closed, open and Likert scale questions. These gathered data on the participants' prior experience of team teaching, explored the value they attributed to team teaching and the challenges they identified following the experience. The questionnaires were piloted to enhance clarity, improve reliability and reduce bias (Cohen, Manion, and Morrison 2011). The entry questionnaire was completed by 22 participants at the first workshop and the exit questionnaire was completed by 24 participants after the second workshop.

In addition, a range of pedagogic activities designed as part of the workshops undertaken were used to encourage reflection and to gather data on the participants' thoughts, feelings and professional judgements relating to team teaching in a naturalistic context (Boote 2008). For example, in the second workshop, Take a Stand was an activity where participants were invited to literally stand by a particular statement that was displayed on the classroom wall. Statements ranged along a continuum from a strongly positive 'I'm a convert to team teaching' to the opposite: 'Never again!' with more nuanced assertions in between such as 'Team teaching is professionally 
rewarding experience' and 'I cannot see how I will be able to use team teaching in the current school system'. We also asked all participants to write out the reasons for their choice and collected these at the end of the session. We also draw on the feedback from principals and teachers who attended the end of project seminar to discuss implications and practical steps for future iterations of this work.

\section{Research analysis}

The first stage of analysis involved collating descriptive statistics relating to the more quantitative elements of the data (Robson 2011). Thematic coding was used to analyse the more open-ended, qualitative data from the questionnaires and the workshop activities. This followed a six-step process to transcribe and organise, read and record initial thoughts, start coding and label, generate categories and themes, represent and interpret (Creswell 2014). The process of data analysis led to the development of smaller sub-categories while some data converged into broader issues based on the frequency of topics and patterns (Bogdan and Biklen 1998).

The findings from the project data are delineated in the next section under five key themes: prior experiences and motivation to be involved; perceived benefits of team teaching for teachers; perceived benefits of team teaching for pupils; the importance of relationships; and constraints to practising team teaching.

\section{Findings}

\section{Prior experience and the motivation to be involved}

The 10 co-operating teachers who completed the entry questionnaire had undertaken their ITE in Ireland. Only one had prior training in team teaching as a student teacher, a finding congruent with the research showing the dearth of team teaching in ITE (Burbank and Kauchak 2003; Hume and Berry 2013). When asked if anyone had had subsequent experience of training, one person responded in the affirmative. Despite the lack of training, however, $73 \%$ of the cohort noted that team teaching was practiced in their schools, with 38\% (8 respondents) saying that team teaching occurred on an almost daily basis. The next highest number of respondents $(24 \%$ or 5 respondents) reported an occurrence of team teaching 'about once a month'. When asked about their involvement in this team teaching in their schools, four of them indicated that they were frequently or quite often involved while all the others indicted that they would engage in it, albeit less frequently. So despite a lack of training there was a relatively strong expectation around teachers' engagement with team teaching in school.

The lack of prior exposure to professional development in relation to team teaching was noted in a number of studies cited in the literature review above (Tobin 2006; Murphy 2011; Thompson et al. 2015) and is evident in our findings also. This, alongside evidence of increasing frequency of team teaching occurring in schools (Shevlin et al. 2009; Baeten and Simons 2014; Fluijt, Bakker, and Struyf 2016), may explain the co-operating schools' eagerness to avail of an opportunity to engage with the project despite a somewhat fraught industrial relations climate that prevailed in schools in 2015. Student teachers were also enthusiastic about it despite there being no credit available for participation: an important consideration given their heavy assignment load. 


\section{Perceived benefits of team teaching for teachers}

The exit questionnaire revealed that the team teaching experience was seen as professionally rewarding by all 24 participants who attended the second workshop. In it the student teachers voiced considerable satisfaction at being involved in the project and valued it for the increased confidence it afforded them. They also reported that it had given them a greater sense of having something to contribute in this professional context. The issue of confidence featured in comments from both co-operating teachers and student teachers:

I am not as insecure about having another teacher in the room with me and I am more confident. (Co-operating teacher: exit questionnaire)

Student teachers felt affirmed in their teaching approaches and reported it had made an impact on their professional growth by '... seeing how a qualified teacher approaches a lesson ...' (Student teacher: exit questionnaire). In the Take a Stand activity, one student teacher chose the statement: 'Team teaching is a professionally rewarding experience'. Her written comment is worth quoting in full:

It was great collaborating with an experienced teacher and to be able to contribute ideas and expand them together. Affirmation of my ability to teach, prepare, research plan/ sharing ideas and resources for other topics. Great to have a professional time and space to discuss these ideas and improve on them through collaboration. (Take a Stand activity: Student teacher)

The impact on a student teacher's sense of self and the affirmation of doing a job well or being capable is particularly noteworthy. This element, while it is only cited by one student teacher in this activity, emerged in the exit survey from a number of respondents as an important outcome of the experience. Feeling affirmed and being valued in this way can be seen in the research from Scantlebury, Gallo-Fox, and Wassell (2008) and Murphy, Carlisle, and Beggs (2009). Such a feeling also infers the greater likelihood of student teachers repeating the experience as qualified teachers (Wassell and LaVan 2009).

By far the most frequently mentioned benefit among the participants concerning team teaching was the idea of sharing resources, ideas and methods of teaching (Eick, Ware, and Williams 2003; Tobin 2006; van Velzen et al. 2012). The high proportion of student teachers in this project may be one reason for the frequency that this was mentioned, but it featured among the co-operating teachers' responses as well with the reciprocal notion of gaining insight into new methods to teach a topic. Team teaching was anticipated as a means of enhancing professional conversations, reflection and even evaluation (Fluijt, Bakker, and Struyf 2016). For example, in the entry questionnaire, one participant noted an anticipated value of the process as being '[C]omparing and observing different techniques, peer assessment and feedback on each other's practices' Another participant, following the workshops, expressed a feeling of being 'refreshed' and 'renewed' with new ideas and resources:

Allowing to see another perspective on how to teach a certain topic or subject and how this is applicable elsewhere in my lessons. (Co-operating teacher: exit questionnaire) 
Team teaching was seen to have enhanced teaching through improvements to classroom management, both in terms of improved pupil behaviour and perhaps more importantly in terms of allowing greater involvement of all pupils in the lesson. Relationships were enhanced by virtue of teachers being able to see more of the pupils' capabilities, '... especially those [students] that are mainly more reserved in class ...' (Co-operating teacher: exit questionnaire). This advantage to teachers was anticipated in the entry questionnaire also: the idea of 'sharing the discipline', 'aiding with differentiation' and 'dealing with mixed-ability' settings and being able to give more attention to individuals thanks to the 'halving' of the teacher-pupil ratio:

Students get "double" the help one-on-one access for asking/answering questions. (Cooperating teacher: entry questionnaire)

\section{Perceived benefits of team teaching for pupils}

The impact of team teaching on pupils' learning permeates the data from the workshops and the exit questionnaire. In the questions about the potential benefits of team teaching, 24 of the respondents strongly agreed (17) or agreed (7) with the statement 'team teaching is of benefit to students'. Equally in the Take a Stand activity, the potential benefit to pupils was what resonated for the most participants (14 out of 25). When probing this idea in more depth, we found that the reasons cited ranged from the enhanced contact time and 'more individual attention' to allowing more time on tasks and higher levels of engagement by pupils. As a result of better teacher-student ratios and more effective group work within the team taught lessons, participants thought that pupils had more opportunities to be engaged in learning and to have their views heard:

They got the opportunity to work in small teams and their voice and opinions were heard. They were actively involved throughout and all were given feedback throughout the lesson. (Co-operating teacher: exit questionnaire)

A concrete benefit to pupils cited was the increase in opportunity to properly differentiate lessons and to give more attention across all ability groups, but especially to 'weaker students' or those with SEN. This resonates strongly with the findings of O’Leary (2015).

Another theme to feature for student teachers was the effect of the interaction between the teachers, an outcome of working together that 'piqued their [the pupils'] attention' (Student teacher: exit questionnaire). The idea of teachers collaborating was also noted as not only a novelty but as the basis of modelling the collaboration as a way to communicate the value teachers place on teamwork:

Within team teaching the students are learning more than content they are learning life skills with teachers as examples (e.g. working together, conflict resolution). (Take a Stand activity)

\section{The importance of relationships}

Research on team teaching is replete with references to the importance of the relationships among the teaching teams, teacher compatibility and questions of parity of esteem that are paramount to the success and sustainability of any team teaching 
initiative (Cook and Friend 1991; Cramer and Nevin 2006; Scruggs, Mastropieri, and McDuffie 2007; Baeten and Simons 2014). This was particularly true in this research project where the power differential between the experienced co-operating teacher and the student teacher was noted by many student teacher participants (Lofthouse and Thomas 2014). This also featured as an issue at the seminar, where one participant noted that team teaching 'could disempower a PME student if introduced too early' (Seminar participant). Relationships emerged as the primary challenge participants perceived from engaging with team teaching at the outset of the project, with issues such as a 'personality clash' (Co-operating teacher: entry questionnaire) and 'competing egos' cited by many (Student teacher: entry questionnaire). When asked in the exit questionnaire about the advice they would give to others considering team teaching, this idea of good rapport emerged strongly and was mentioned in different ways, such as: 'Choose the team teacher carefully' 'Be prepared and link with someone on the same path as you. Matching personalities'. It is not clear whether the advice arises from experiences of good or poor relations but some of the feedback provides insight into what Carambo and Stickney (2009) refer to the as the opportunities for learning even where differences occur between teachers. Participants noted that differences in teaching styles were evident but these were more often seen as opportunities to experience different ways of teaching content. This would need time and an openness to discuss and overcome, particularly in situations where team teaching is new.

Most comments advising novice team teachers however were encouraging and enthusiastic with remarks like 'Be confident and enjoy!' or 'Go for it - need a good rapport with other teacher, but you have to try it before you bash it!' The dominant message in the advice was to 'plan, plan and plan some more', conveying the sense that establishing rapport would be assured once there was clarity about roles and responsibilities.

\section{Constraints to team teaching}

In the Take a Stand activity, a relatively large number of the participants (9) stood by the statement: 'I cannot see how I will be able to use team teaching within the current school system'. The scepticism was mostly explained by reference to 'time constraints' for planning or 'financial restrictions'. While some of this group also noted the benefits to pupils and used words like 'worthwhile' and 'rewarding', this statement resonated for them most and regardless of the putative benefits they felt it was an unworkable proposition. As one person summed it up:

Nice idea but somewhat unrealistic/ not enough resources are made available for it. (Take a Stand activity)

The most frequently cited obstacle to successful team teaching in schools related to planning time, timetabling and even time for activities within lessons. With respect to lesson planning, we were conscious of an added time constraint owing to the student teachers being in the school for only two days a week so we put additional supports in place to accommodate teachers' planning time (co-operating teachers could avail of a half day substitute cover to facilitate planning of the lesson(s) with their student teacher). It emerged, however, that despite provision of this support, most of the teachers did not draw on it, preferring to teach their classes and plan in the 
times when both they and the student teacher were not in class. They tapped into the substitution cover only when it was necessary to leave the school to attend the workshops and seminar. Lesson planning involving two people was also seen to require more time than when a teacher plans lessons alone. Planning was considered 'too time-consuming' and only 'worthwhile if you have a large group that you want to do active learning with'. The short length of time available for most lessons (generally 40 minutes) was also considered a constraint.

However, references to time for reflection or evaluation are much less frequent than concerns expressed about time for planning. This project required the teams to review the lesson they taught in the second workshop and to co-create a poster that effectively pushed them to co-reflect on it and share their learning. Given the time constraints and workloads of those involved it is not clear whether teachers would have taken the time to engage in co-reflection had this not been required. Again, this is an important consideration in the future development of the process if even those committed to team teaching cannot prioritise time for review as well as planning. It has particular repercussions for the development of Professional Learning Communities (PLCs) which, as we have seen, require continued collaboration and collective reflective practice (Bolam et al. 2005; Lieberman and Miller 2008; Kim and Silver 2016).

Participants also reported that in certain instances, team teaching wasn't necessarily beneficial to pupils and a clear rationale for its use would be necessary. In some lessons it had led to some confusion on the part of the pupils, who were 'unsettled' by having two teachers or 'were unsure who they should be looking at' or uncertain as to 'who, if anyone, was in charge' (Student teacher: exit questionnaire). If team teaching is not part of the school culture, it was also felt that it 'would take a little time to embed the idea of team teaching as it is not practised in our school' (Cooperating teacher: exit questionnaire).

\section{Conclusion and next steps}

Overall, the findings of the research project have been overwhelmingly positive concerning co-operating teachers' and student teachers' engagement with the process, most of whom had no previous professional experience nor preparation for team teaching. This relates both to positive attributes they perceive for themselves as professional learners and for their pupils' learning. Moreover, the data indicate that both student teachers and co-operating teachers used the 'space' provided by the project to reflect on their own practice and to challenge assumptions they may have held in relation to teaching and learning (Carambo and Stickney 2009; van Velzen et al. 2012).

The challenges cited in the research literature also emerged as issues in this research, most notably time for planning and reflection and the importance of relationships (Baeten and Simons 2014; Fluijt, Bakker, and Struyf 2016). These were noted in the data of almost all participants, yet the apprehension about these had dissipated following engagement in the process. This indicates the desirability of providing opportunities for engagement in collaborative activities so that teachers can use their professional expertise to negotiate challenges rather than remain fearful of them in an abstract sense (Shevlin et al. 2009). It has also challenged us to reassess and reorient current approaches on the PME programme to better prepare student teachers for their careers in post-primary schools (Wassell and LaVan 2009; Hume and Berry 
2013). But as noted in our findings the view of teachers is that change is not likely without sustained resourcing to match the vision for collaborative practice that is set out in policy at a national level. A most noteworthy finding is the importance that experienced teachers attach to contact time with their pupils. Even when supports were provided to facilitate planning and reflection for co-operating teachers, many chose to forgo this opportunity rather than miss class. This raises concern about the level of reflection possible (Fluijt, Bakker, and Struyf 2016) and the formation of shared values and vision about educational practice (Wassell and LaVan 2009).

A review of the outcomes of the project at university level and in conjunction with our partners in the PDST has resulted in the planning of a more extensive team teaching research project since this initial pilot was implemented. The development was also informed by suggestions from participants at the team teaching seminar in April 2015. Recommendations made on the day included making team teaching an integral and accredited part of the whole PME programme and extending the experience over a longer time frame. As a result, the team teaching initiative has been reconceptualised and extended. This involves the rollout workshops for all PME student teachers (approx. 130 student teachers) in the second year of the programme, to which a cooperating teacher from their placement school will be invited to attend with the support of the PDST. Introducing the process to second year students affords more lead-in time for PMEs to gain confidence and develop their own teaching style prior to working in a team teaching setting and addresses the concern about introducing team teaching too soon (Murphy, Carlisle, and Beggs 2009). A wider benefit is that it strengthens our work with and support for partner schools and co-operating teachers around the theme of team teaching. Moreover, it creates further opportunities for us to contribute to the emerging literature in the area and to deepen the practical engagement with collaboration on placement schools in authentic ways.

Considering the reported low levels of teacher collaboration and the feeling of isolation felt by many post-primary teachers (Hogan et al. 2007; Gleeson 2012), it is hoped that NQTs entering the system in Ireland in future will have the professional capacity and confidence to engage with a changing educational landscape that requires increased levels of collaboration and co-operation. The pilot project reported on here represents an initial step towards that aim and has not only enhanced our vision for greater collaborative practice among future teachers but has contributed to stronger emphasis on collaboration for our practice as teacher educators.

\section{Notes on contributors}

Angela Rickard is a lecturer in the Maynooth University Department of Education. She teaches on a number of undergraduate and Masters programmes. She is concerned with ways that emerging technologies can be used to support creative approaches to teaching and learning. She undertaken a number of research initiatives on themes including Educational Technology (especially the use of digital video in initial teacher education), Development Education and Teacher Professional Development.

Thomas Walsh is a lecturer in the Maynooth University Department of Education. His main teaching and research interests include history of education, early childhood education, school-university partnerships, school inspection and evaluation, and curriculum development and implementation. Prior to joining Maynooth University, he worked as a primary school teacher, as a researcher in the field of early childhood education and as an inspector with the Department of Education and Skills. 


\section{References}

Baeten, M., and M. Simons. 2014. "Student Teachers' Team Teaching: Models, Effects, and Conditions for Implementation." Teaching and Teacher Education 41: 92-110.

Ball, D. L., and D. K. Cohen. 1999. "Developing Practice, Developing Practitioners: Toward a Practice-Based Theory of Professional Education." In Teaching as the Learning Profession: Handbook of Policy and Practice, edited by G. Sykes and L. Darling-Hammond, 3-32. San Francisco: Jossey Bass.

Barnett, R. 1997. Higher Education: A Critical Business. Buckingham: SRHE/Open University Press.

Bates, K. 2005. "A Post-Primary Perspective on Team-Teaching.” Cabhair 1: 5-12.

Biesta, G. 2011. "From Learning Cultures to Educational Cultures: Values and Judgements in Educational Research and Educational Improvement." International Journal of Early Childhood 43: 199-210.

Bogdan, R., and S. Biklen. 1998. Qualitative Research for Education: An Introduction to Theory and Methods. Boston: Allyn and Bacon.

Bolam, R., A. McMahon, L. Stoll, S. Thomas, and M. Wallace. 2005. Creating and Sustaining Effective Professional Learning Communities. London: DfES Publications.

Boote, D. 2008. "Notes Toward a Naturalistic Study of Education Research Methodology." Interchange 39: 303-325.

Bowen, G. 2009. "Document Analysis as a Qualitative Research Method.” Qualitative Research Journal 9 (2): 27-40.

British Educational Research Association. 2014. Research and the Teaching Profession. Building the Capacity for a Self-Improving Education System. London: BERA.

Brown, J. S., A. Collins, and P. Duguid. 1989. "Situated Cognition and the Culture of Learning." Educational Researcher 18: 32-42.

Burbank, M. D., and D. Kauchak. 2003. "An Alternative Model for Professional Development: Investigations into Effective Collaboration." Teaching and Teacher Education 19 (5): 499514.

Carambo, C., and C. T. Stickney. 2009. "Co-teaching Praxis and Professional Service: Facilitating the Transition of Beliefs and Practices." Cultural Studies of Science Education 4 (2): 433-441.

Cohen, L., L. Manion, and K. Morrison. 2011. Research Methods in Education. 7th ed. New York; London: Routledge Falmer.

Conway, P. 2002. "Learning in Communities of Practice: Rethinking Teaching and Learning in Disadvantaged Contexts." Irish Educational Studies 21: 61-91.

Cook, L., and M. Friend. 1991. "Principles for the Practice of Collaboration in Schools." Preventing School Failure: Alternative Education for Children and Youth 35 (4): 6-9.

County Cork VEC. 2011. Team Teaching-Guidelines for Schools/ Colleges. Cork: County Cork VEC.

Cramer, E., and A. Nevin. 2006. "A Mixed Methodology Analysis of Co-teacher Assessments: Implications for Teacher Education." Teacher Education and Special Education: The Journal of the Teacher Education Division of the Council for Exceptional Children 29: 261-274.

Creswell, J. 2014. Research Design: Qualitative, Quantitative and Mixed Methods Approaches. 4th ed. Thousand Oaks: Sage.

Department of Education and Science. 1998. Education Act. Dublin: The Stationery Office.

Department of Education and Science. 2007. Inclusion of Students with Special Educational Needs, Post-Primary Guidelines. Dublin: The Stationery Office.

Department of Education and Skills. 2011. Literacy and Numeracy for Learning and Life. Dublin: Department of Education and Skills.

Department of Education and Skills. 2012. Framework for Junior Cycle. Dublin: Department of Education and Skills.

Department of Education and Skills. 2014. Circular 70/2014 - Guidance for Post-Primary Schools on the Provision of Resource Teaching and Learning Support. Dublin: DES.

Department of Education and Skills. 2016a. School Self-Evaluation Guidelines 2016-20: PostPrimary. Dublin: Department of Education and Skills.

Department of Education and Skills. 2016b. Looking at Our Schools 2016: A Quality Framework for Post-Primary Schools. Dublin: Department of Education and Skills. 
Department of Education and Skills. 2018. Chief Inspector's Report January 2013-July 2016: Excellence in Learning for All. Dublin: Department of Education and Skills. https://www. education.ie/en/Publications/Inspection-Reports-Publications/Evaluation-Reports-Guidelines/ insp_chief_inspectors_report_2013_2016.pdf.

Dieker, L. 2015. "Cooperative Teaching." Accessed August 10, 2016. http://www. specialconnections. ku.edu/?q=collaboration/cooperative_teaching.

Dieker, L. A., and W. W. Murawski. 2003. "Co-teaching at the Secondary Level: Unique Issues, Current Trends, and Suggestions for Success." The High School Journal 86: 1-13.

Eick, C., F. Ware, and P. Williams. 2003. "Co-teaching in a Science Methods Course: A Situated Learning Model of Becoming a Teacher." Journal of Teacher Education 54 (1): 74-85.

Fluijt, D., C. Bakker, and E. Struyf. 2016. "Team-Reflection: The Missing Link in Co-teaching Teams." European Journal of Special Needs Education 31 (2): 187-201.

Friend, M., L. Cook, D. Hurley-Chamberlain, and C. Shamberger. 2010. "Co-Teaching: An Illustration of the Complexity of Collaboration in Special Education." Journal of Educational and Psychological Consultation 20: 9-27.

Gleeson, J. 2012. "The Professional Knowledge Base and Practice of Irish Post-Primary Teachers: What is the Research Evidence Telling Us?" Irish Educational Studies 31 (1): 1-17.

Government of Ireland. 2004. Education for Persons with Special Educational Needs Act. Dublin: The Stationery Office.

Gray, C. 2013. "Bridging the Teacher/Researcher Divide: Master's-Level Work in Initial Teacher Education.” European Journal of Teacher Education 36 (1): 24-38.

Hattie, J. A. 2009. Visible Learning. Oxford: Routledge.

Hogan, P., A. Brosnan, B. de Róiste, A. MacAlister, A. Malone, N. Quirke-Bolt, and G. Smith. 2007. Learning Anew: Final Report of the Research and Development Project: Teaching and Learning for the 21st Century 2003-07. Maynooth: Department of Education, Maynooth University.

Hume, A., and A. Berry. 2013. "Enhancing the Practicum Experience for Pre-service Chemistry Teachers through Collaborative CoRe Design with Mentor Teachers." Research in Science Education 43 (5): 2107-2136.

Inclusive Education in Action. 2016. Team Teaching for Professional Development and Inclusion (Ireland). http://www.inclusive-education-in-action.org/example-119.html.

Irish Association of Teachers in Special Education. 2000. National Survey of Special Needs Resource Teachers in Primary Schools. Dublin: IATSE.

Irish National Teachers' Organisation. 1984. Co-operative Teaching in Shared Area Classrooms - A Report by the Education Committee. Dublin: Irish National Teachers' Organisation.

Kim, Y., and R. Silver. 2016. "Provoking Reflective Thinking in Post Observation Conversations." Journal of Teacher Education 67 (3): 203-219.

Kincheloe, J. L. 2012. Teachers as Researchers: Qualitative Inquiry as a Path to Empowerment. London and New York: Routledge (Classic Edition).

Lieberman, A., and L. Miller. 2008. Teachers in Professional Communities: Improving Teaching and Learning. New York: Teachers College Press.

Lofthouse, R., and U. Thomas. 2014. "Mentoring Student Teachers; a Vulnerable Workplace Learning Practice." International Journal of Mentoring and Coaching in Education 3 (3): 201-218.

McKenna, A. 1982. "Shared Area Teaching in Ireland - Some Initial Responses." An Múinteoir Náisiúnta 26 (2): 25-28.

McNamara, S. 2010. Perspectives on Co-teaching as a Means of Meeting the Needs of Students with Special Educational Needs within the Mainstream Class in a Second-Level All Boys' Catholic, Fee-Paying School. Unpublished M.SEN thesis, St. Patrick's College, Dublin.

Miller, P., and V. Stayton. 1999. "Higher Education Culture-A Fit or Misfit with Reform in Teacher Education?" Journal of Teacher Education 50 (4): 290-302.

Murawski, W. W., and H. Lee Swanson. 2001. "A Meta-Analysis of Co-teaching Research: Where are the Data?" Remedial and Special Education 22 (5): 258-267.

Murphy, F. 2011. Team-Teaching for Inclusive Learning: Purposes, Practices and Perceptions of a Team-Teaching Initiative in Irish Post-Primary Schools. Unpublished Ph.D Thesis, University College Cork. 
Murphy, C. 2016. Coteaching in Teacher Education: Innovative Pedagogy for Excellence. St Albans: Critical Publishing.

Murphy, C., K. Carlisle, and J. Beggs. 2009. "Can They Go It Alone? Addressing Criticisms of Coteaching." Cultural Studies of Science Education 4 (2): 461-475.

National Council for Special Education. 2011. Inclusive Education Framework: A Guide for Schools on the Inclusion of Pupils with Special Educational Needs. Meath: NCSE.

National Council for Special Education. 2013. Supporting Students with Special Educational Needs in Schools - NCSE Policy Advice Paper No. 4. Meath: NCSE.

National Council for Special Education. 2015. Statistics: Resource Teaching and SNA Allocations to Schools. Meath: NCSE.

National Educational Psychological Service. 2010. A Continuum of Support for Post-Primary Schools. Dublin: Department of Education and Skills.

Nolan, M. 2005. “To Withdraw or Not to Withdraw?" Learn 27: 56-60.

O'Gorman, E., S. Drudy, E. Winter, R. Smith, and M. Barry. 2009. Professional Development for Post-Primary Special Educational Needs (SEN) Teachers in Northern Ireland and the Republic of Ireland - A Report for the Standing Conference on Teacher Education North and South (SCoTENS). Armagh: The Centre for Cross Boarder Studies.

O'Leary, S. 2015. "A Continuum of Support, Collaboration and Co-teaching: A Post-Primary Case Study." South East Education Centre Research Journal 1: 126-137.

Organisation for Economic Co-operation and Development. 1991. Reviews of National Policies for Education - Ireland. Paris: OECD.

Organisation for Economic Co-operation and Development. 2009. Creating Effective Teaching and Learning Environments: First Results from TALIS. Paris: OECD.

Rickard, A., and M. Dempsey. 2013. Critical Reflection in Science Teaching and Learning: A Creative Approach to the Introduction to Teaching Practice. Scotens Annual Report 2013. Armagh: The Centre for Cross Boarder Studies.

Rix, J., K. Sheehy, F. Fletcher-Campbell, M. Crisp, and A. Harper. 2013. Continuum of Education Provision for Children with Special Educational Needs: Review of International Policies and Practices. Report Commissioned by the NCSE. Meath: NCSE.

Robson, C. 2011. Real World Research: A Resource for Users of Social Research Methods in Applied Settings. 3rd ed. Chichester: Wiley.

Roth, W. M., and K. Tobin. 2002. At the Elbow of Another: Learning to Teach by Coteaching. New York: Peter Lang.

Scantlebury, K., J. Gallo-Fox, and B. Wassell. 2008. "Coteaching as a Model for Preservice Secondary Science Teacher Education.” Teaching and Teacher Education 24 (4): 967-981.

Scruggs, T., M. Mastropieri, and K. McDuffie. 2007. "Co-teaching in Inclusive Classrooms: A Metasynthesis of Qualitative Research." Exceptional Children 73: 392-416.

Shevlin, M., H. Kearns, M. Ranaghan, M. Twomey, R. Smith, and E. Winter. 2009. Creating Inclusive Learning Environments in Irish Schools: Teacher Perspectives. Meath: NCSE.

Simmons, R., and K. Magiera. 2007. "Evaluation of Co-teaching in Three High Schools within One District: How Do You Know When You Are TRULY Co-teaching?" Teaching Exceptional Children Plus 3 (3): 1-12.

Tabachnick, B. R., and K. M. Zeichner. 1991. Issues and Practices in Inquiry-Oriented Teacher Education. New York: Falmer Press.

Teachers' Union of Ireland, Association of Secondary Teachers Ireland and the Department of Education and Skills. 2015. Junior Cycle Reform Joint Statement on Principles and Implementation. Dublin: TUI, ASTI and DES.

Teaching Council. 2011. Policy on the Continuum of Teacher Education. Maynooth: Teaching Council.

Teaching Council. 2013. Guidelines on School Placement. 1st ed. Maynooth: Teaching Council.

Teaching Council. 2016. Cosán - Framework for Teachers' Learning. Maynooth: Teaching Council.

Thompson, J., S. Hagenah, K. Lohwasser, and K. Laxton. 2015. "Problems Without Ceilings: How Mentors and Novices Frame and Work on Problems-of-Practice." Journal of Teacher Education 66 (4): 363-381.

Tobin, K. 2006. "Learning to Teach through Co-teaching and Co-generative Dialogue." Teaching Education 17 (2): 133-142. 
Travers, J., T. Balfe, C. Butler, T. Day, M. Dupont, R. McDaid, M. O'Donnell, and A. Prunty. 2010. Addressing the Barriers and Challenges to Inclusion in Irish Schools. Dublin: Special Education Department, St Patrick's College.

van Velzen, C., M. Volman, M. Brekelmans, and S. White. 2012. "Guided Work-Based Learning: Sharing Practical Teaching Knowledge with Student Teachers." Teaching and Teacher Education 28 (2): 229-239.

Villa, R., J. Thousand, and A. Nevin. 2008. A Guide to Co-teaching: Practical Tips for Facilitating Student Learning. London: Sage.

Wassell, B., and S. K. LaVan. 2009. "Tough Transitions? Mediating Beginning Urban Teachers' Practices through Coteaching." Cultural Studies of Science Education 4 (2): 409-432.

Weiss, M., and F. Brigham. 2000. "Co-teaching and the Model of Shared Responsibility: What Does the Research Support?" In Educational Interventions: Advances in Learning and Behavioral Disabilities, Vol. 14, edited by T. Scruggs and M. Mastropieri, 217-245. Stamford, CT: JAI.

Welch, M., K. Brownell, and S. M. Sheridan. 1999. "What's the Score and Game Plan on Teaming in Schools?" Remedial and Special Education 20: 36-49.

Zeichner, K. 2002. "Beyond Traditional Structures of Student Teaching." Teacher Education Quarterly 29 (2): 59-64. 